\title{
Introduction to Abstractionism
}

\author{
Philip A. Ebert and Marcus Rossberg \\ 1.1 WHAT IS ABSTRACTIONISM?
}

Abstractionism in philosophy of mathematics has its origins in Gottlob Frege's logicism-a position Frege developed in the late nineteenth and early twentieth century. Frege's main aim was to reduce arithmetic and analysis to logic in order to provide a secure foundation for mathematical knowledge. As is well known, Frege's development of logicism failed. The infamous Basic Law Vone of the six basic laws of logic Frege proposed in his magnum opus Grundgesetze der Arithmetik-is subject to Russell's Paradox. The striking feature of Frege's Basic Law V is that it takes the form of an abstraction principle. The general form of an abstraction principle can by symbolised like this: ${ }^{1}$

$$
\S(\alpha)=\S(\beta) \leftrightarrow \alpha \sim \beta
$$

where ' $\S$ ' is a term-forming operator applicable to expression of the type of $\alpha$ and $\beta$, and $\sim$ is an equivalence relation on entities denoted by expressions of that type. Accordingly, abstraction principles are biconditionals that feature an equivalence relation on the right-hand side and an identity statement on the left-hand side. The abstracta denoted by the terms featuring in the identity statement on the left are taken to be introduced, in some sense, by the abstraction principle, giving the equivalence on the right-hand side conceptual priority over them. More on this below.

Frege's ill-fated Basic Law V, involves co-extentionality (of functions) as the relevant equivalence relation on the right-hand side, introducing, what Frege termed value-ranges, $\dot{\varepsilon} \varphi(\varepsilon)$, on the left: ${ }^{2}$

\footnotetext{
${ }^{1}$ Here and below, we will omit prefixed universal quantifiers in abstraction principles. We are thereby in effect neglecting the distinction between schematic and axiomatic (or universal) formulations of abstraction principles. In the context of full impredicative second-order logic, these formulations are equivalent, but in systems with weaker second-order comprehension (see p. 19 below), these come apart: the schematic formulations entail the axiomatic ones, but not vice versa; see e.g. Heck (1996, \$1), Fine (2002, pp. 36-38), or Linnebo (2004, p. 158).

${ }^{2}$ In words: The value-range of function $f$ is identical to the value-range of function $g$ if and only if $f$ and $g$ have the same value for any argument. The value-range of a function is roughly
} 


$$
\dot{\varepsilon} f(\varepsilon)=\dot{\varepsilon} g(\varepsilon) \leftrightarrow \forall x(f(x)=g(x))
$$

Ultimately, Frege was unable to find a suitable alternative for his Basic Law V (more on this in $\$ 2$ below) and gave up on his logicist project. ${ }^{3}$ In the latter half of the twentieth century, logicism enjoyed a revival. Its main catalyst was Crispin Wright's Frege's Conception of Numbers as Object, published in 1983. Wright soon joined forces with Bob Hale and together they developed and defended a view now often referred to as "neo-Fregeanism" or sometimes more specifically as the "Scottish school of neo-Fregeanism". ${ }^{4}$ The main tenet of neo-Fregeanism is to revive a version of Frege's logicism by substituting the inconsistent Basic Law V with a principle called Hume's Principle. Like Basic Law V, Hume's Principle is an abstraction principle:

Hume's Principle (HP)

$$
N x: F x=N x: G x \leftrightarrow F \approx G
$$

where ' $N x: F x$ ' stands for "the (cardinal) number of $F \mathrm{~s}$ " and ' $\approx$ ' denotes the equivalence relation of equinumerosity between concepts. ${ }^{5}$ Hume's Principle was, of course, considered by Frege in his Grundlagen der Arithmetik in 1884. He rejected it, however, considering it ill-suited as a foundation for arithmetic (more on this below). It was not until Geach (1955) that this way to revive a version of Frege's Logicism was reconsidered. Geach claimed that Frege's decision to identify numbers with extensions was questionable and suggested that one could prove the infinity of the number series without drawing on "any

what we would call its graph today. In the special case of concepts, the value-range is the extension of the concept. Concepts $F$ and $G$ have the same extensions if and only they are co-extensional (i.e., the same objects fall under them): $\dot{\varepsilon} F \varepsilon=\dot{\varepsilon} G \varepsilon \leftrightarrow \forall x(F x \leftrightarrow G x)$

${ }^{3}$ As we now know, if embedded in a weaker logic-e.g., predicative second-order logic-Basic Law V does not entail a contradiction. This has generated some very interesting research on identifying consistent fragments of Frege's Grundgesetze logic that retain Basic Law V-for further details see $\$ 1.3$ below. For all we know, Frege never considered a weakening of the logic as a way out of the paradox. Indeed, it might seem to go against Frege's general conception of logic.

${ }^{4}$ In his excellent critical survey, MacBride (2003) distinguishes "neo-logicism" from "neoFregeanism”. Neo-logicism stands for "the doctrine that Frege's judgement was premature [...] Frege should not have abandoned (HP)" (p. 106) while "neo-Fregeanism" stands for the general conception of the relation between language and reality that Hale and Wright are interpreted to have adopted. We here use the term "neo-Fregeanism" to stand for Hale and Wright's version of Abstractionism generally.

${ }^{5} \mathrm{HP}$ may be glossed as: the cardinal number belonging to the concept $F$ is identical to the cardinal number belonging to the concept $G$ if and only if there is a one-to-one correspondence between the objects falling under $F$ and those falling under $G$. The equivalence relation of equinumerosity (one-to-one correspondence, bijection) can be formulated in purely (second-order) logical vocabulary. In full detail, HP is the following statement:

$$
N x: F x=N x: G x \leftrightarrow
$$

$\exists R(\forall x[F x \supset \exists y(G y \wedge R x y \wedge \forall z(G z \wedge R x z \supset z=y))] \wedge$

$\forall y[G y \supset \exists x(F x \wedge R x y \wedge \forall z(F z \wedge R z y \supset z=x))])$ 
“Abstractionism_OUP_for_copyediting” - 2016/4/20 - 11:40 - page 3 - \#12

special set theory" (Geach, 1955, p. 569). In 1965, Charles Parson went a step further and noted explicitly that the derivation of the axioms of arithmetic "could be carried out by taking [Hume's Principle] as an axiom" (Parsons, 1965, p. 194).

It was, however, not until Wright (1983) that such proof was presented. Here, Wright proves that the axioms of arithmetic can be derived from Hume's Principle using second-order logic and Frege's definition of zero, predecession, and natural number. Following Boolos (1990), the proof is now known as Frege's Theorem. ${ }^{6}$

Wright not merely establishes Frege's Theorem; he also offers the first robust philosophical defense of Hume's Principle as a foundational principle. In contrast to Frege, who considered his Basic Law V to be a logical law, Wright does not take Hume's Principle to be purely logical but regards it more akin to a definition or explanation of the concept CARDINAL NUMBER. ${ }^{7}$ What is important here in particular is the status of Hume's Principle as an abstraction principle: the fact that Hume's Principle takes the form of an abstraction principle makes it especially suited as an explanation of the concept CARDINAL NUMBER and thus as a foundational principle.

So understood, we can regard neo-Fregeans among the main proponents of Abstractionism: the view that abstraction principles play a crucial role in the proper foundation of arithmetic, analysis, and possibly other areas of mathematics. Abstractionism therefore has two main aspects, a mathematical and a philosophical one. The main aim of the mathematical aspect of any abstractionist programme is the mathematics of abstraction-bluntly put: proving mathematical theorems about abstraction principles or taking abstraction principles as basic axioms and investigating the resulting theories. A primary aim is to capture various mathematical theories, such as arithmetic, analysis, complex analysis, or set theory as deriving from a few basic abstraction principles and (versions of) higher-order logic. Frege's Theorem is one of the most important result for a mathematical Abstractionist, and numerous other interesting results have been discovered since. ${ }^{8}$

The philosophical aspect of Abstractionism is to offer a philosophical account of why it is beneficial to adopt abstraction principles as foundations for arithmetic or other mathematical theories. Broadly speaking, we can distinguish three kinds of philosophical themes concerning philosophical Abstractionism: semantic, epistemological, and ontological.

What we call semantic Abstractionism ${ }^{9}$ is the thesis that our capacity to

${ }^{6}$ Compare also Heck (2011a, 2012), who provides an insightful and detailed account of the history of Frege's Theorem and discusses the question whether Frege himself was aware of this theorem.

${ }^{7}$ In fact, this is in stark contrast to Frege. In his Grundgesetze, Frege notes that Basic Law V is not to be understood as a definition of the concept VALUE-RANGE; see Frege $(1903, \mathbb{\$} 146$ ).

${ }^{8}$ See $\$ 1.3$ below, were we will provide a short overview of some technical results.

${ }^{9}$ Semantic Abstractionism is sometimes identified with Abstractionism simpliciter, see e.g. Heck (2011a), p. 14. 
have singular thoughts about objects of a certain type derives from and is constituted by an appreciation of the truth-conditions of identity judgements about objects of that type. The identity judgements involve the fundamental way of referring to objects of that type. The crucial claim of semantic Abstractionism is then that the truth-conditions of such identity judgements can be given by means of an abstraction principle, involving an equivalence relation of the relevant kind. Connected to this thesis is the claim often made by semantic abstractionists that abstraction principles are not only ideally suited to provide for our capacity of singular thought but also that they can introduce us to a new concept.

To explain the main claim of semantic Abstractionism, let us briefly consider a more "mundane" type of abstraction principle:

\section{Abstraction Principle for Directions $\left(\mathrm{AP}_{d}\right)$}

The direction of line $a$ equals the direction of line $b$

if and only if line $a$ and line $b$ are parallel.

$$
d(x)=d(y) \leftrightarrow x / / y
$$

Based on this abstraction principle (featuring parallelism of lines as the relevant equivalence relation), we can grasp the concept DIRECTION. Given that identity judgements involve the fundamental way of referring to objects of this kind, it is by means of $\mathrm{AP}_{d}$ that we can have singular thoughts about the objects falling under the concept DIRECTION. Abstraction principles thus provide a way of grasping and apprehending objects, in particular abstract objects such as directions or numbers. ${ }^{10}$ Contributions in Part II of this volume discuss various issues relating to semantic Abstractionism.

Epistemic Abstractionism is the view that abstraction principles are, in some sense, epistemically innocent. The basic claim is that abstraction principles, or at least those abstraction principles that fulfill certain criteria for being "good", are ideally suited to be warrantedly accepted as basic principles. ${ }^{11}$ As early as 1983, Wright made the claim that Hume's Principle qua abstraction principle, is epistemically innocent given its status as a kind of definition:

"The fundamental truths of number theory would be revealed as consequences of an explanation: a statement whose role is to fix the character of a certain concepts."

${ }^{10}$ As we will discuss later, Frege himself rejected abstraction principles as genuinely conceptconstitutive by raising what is now known as the Julius Caesar problem, see $\$ 1.2$ below. The neo-Fregeans have offered numerous solutions to the problem, such as Wright (1983) and Hale and Wright (2001b). For more recent challenges against semantic abstractionism compare Part II of this volume. For further discussion of the neo-Fregean solution of the Caesar problem in particular, see Sullivan and Potter (1997), Stirton (2003), Potter and Sullivan (2005), Pedersen (2009), and Kim (2011), amongst others. For a response to Potter and Sullivan see Hale and Wright (2008).

${ }^{11}$ Establishing the correct criteria for distinguishing "good" from "bad" abstraction principle is a difficulty known as the Bad Company objection, which we will discuss in a little more detail in $\$ 1.5$ below. 
“Abstractionism_OUP_for_copyediting” - 2016/4/20 - 11:40 - page 5 - \#14

(Wright, 1983, p. 153)

As a result, Hume's Principle itself was regarded as a definition and so as an analytic truth that merely fixes the truth conditions of the concept of number. George Boolos and others opposed this conception of Hume's Principle as an analytic definition due to its substantial ontological commitments. ${ }^{12}$

There are other attempts to justify the foundational status of Hume's Principle, e.g. in Hale and Wright (2000), it is regarded as a specific type of stipulative implicit definition which explains our non-inferential a priori knowledge of Hume's Principle. ${ }^{13}$ In the latest development of epistemic Abstractionism, it is argued that we have an entitlement, i.e. a certain type of non-evidential and non-inferential warrant, to accept Hume's Principle. What combines all these approaches is the underlying thought that Hume's Principle qua abstraction principle is concept-constituting or analytic of the concept CARDINAL NUMBER: we are (defeasibly) warranted to accept the principle because of its meaningconstituting character. It is here where epistemic Abstractionism draws on views defended by semantic Abstractionism. Contributions in Part III of this volume develop and discuss new forms of epistemic Abstractionism.

The thesis we call ontological Abstractionism is the view that good abstraction principles introduce new terms referring to sui generis objects. That is, in the case of Hume's Principle, the number-terms so introduced refer to sui generis abstract objects, namely cardinal numbers. ${ }^{14}$ Thus, an ontological abstractionist defends a broadly platonist metaphysical picture of mathematical objects. However, this view has not gone unchallenged: Michael Dummett, one of the staunchest critics of the Neo-Fregean programme, repeatedly takes issue with the platonist aspects of ontological Abstractionism. ${ }^{15}$ Contributions in Part II of this volume continue this line of criticism and question to what extend abstraction principles are indeed compatible with a broadly platonist conception of mathematical objects.

\subsection{HISTORY OF ABSTRACTIONISM}

Philosophers and mathematicians have entertained abstraction principles before Frege. Also his contemporaries, such as Dedekind, von Staudt, Plücker, Stolz, Klein, Schlömilch, and Grassmann have used ideas that underlie, or are similar to, Frege's method of abstraction. ${ }^{16}$ Given that Frege's work on abstraction principles has been the most influential in recent debates and given

${ }^{12}$ Compare Field (1984a,b) and Boolos (1997); see Wright (1999), Hale (1994a), and Ebert (2008) for responses. See also Shapiro and Weir (2000) and Potter and Smiley (2001).

${ }^{13}$ See e.g. Rayo (2003), Ebert (2005b), or MacFarlane (2009) for criticism.

${ }^{14}$ There is a stronger view in the vicinity, first defended in Hale (1987) that all sui generis abstract objects can be captured by appropriate abstraction principles.

${ }^{15}$ See his Dummett (1981a), Dummett (1981b), and Dummett (1991) for a discussion of some his criticism, see for example MacBride (2003) and Ebert (2015).

${ }^{16}$ To what extend Frege was or might have been influenced by his contemporaries and teachers is discussed in Wilson (1992, 2010), Tait (1996), and Mancosu (2015a, forthcoming). For a general 
“Abstractionism_OUP_for_copyediting” - 2016/4/20 - 11:40 - page 6 - \#15

that current forms of Abstractionism take Frege's work as their starting point, it is here where we begin our overview.

Frege develops his logicist account of arithmetic in Die Grundlagen der Arithmetik (1884). His project started with the publication of Begriffsschrift in 1879, which also marks the birth of modern logic. What led him to the development of his logic, concept-script, was the need for an appropriate tool to develop his logicist programme. Frege writes:

The approach was here the following: first I attempted to reduce the concept of ordering in a series to that of logical sequence in order to proceed from here to the concept of number. To prevent anything intuitive from penetrating here unnoticed, everything had to depend on the gaplessness of the chain of inference. In striving to comply with this demand in the strictest possible way, I found an obstacle in the inadequacy of language; the more complex the relations became, the less I was able, given the resulting unwieldiness of expressions, to attain the precision that my aim required. This need then led me to the idea of the present concept-script.

(Frege, 1879, p. IV)

The requirement of gaplessness of the chains of inference is a theme that remained at the heart of the logicist project. Begriffsschrift, however, was not all too well received by his contemporaries-a trend that continued with the poor reception of his main work, Grundgesetze der Arithmetik (1893/1903). ${ }^{17}$ Before publishing his Grundgesetze, a precursor of which already existed as a nearly complete manuscript around $1882,{ }^{18}$ Frege published Die Grundlagen der Arithmetik intended as a more accessible introduction. ${ }^{19}$ It contains in its first part criticisms of well-known approaches to the philosophy of arithmetic, proffered by Mill and Kant, and Frege's contemporaries such as Schröder, Cantor, Hankel, and others. In the second part of Grundlagen, Frege develops his logicism: the thesis that arithmetic is reducible to logic plus explicit definitions and that therefore our arithmetical knowledge is grounded in our logical knowledge.

We will here focus only on $\$ \$ 62-69$ of Grundlagen, which Dummett regards as the "most brilliant and philosophically most fruitful [passages] in the book and the most important for Frege's philosophy of mathematics, and, indeed, his philosophy generally" (Dummett, 1991, p. 111). It is here that Frege performs the often celebrated linguistic turn, and it is here that he first considers an abstraction principle-Hume's Principle-as an answer to the most basic question: "How, then, is a number given to us, if we do not have any

account of the role of abstraction in the nineteenth century and its relation to Greek mathematics see Stein (1990).

${ }^{17}$ See in particular Frege's Foreword to Grundgesetze, pp. X-XI, where he complains about the lack of reception of his work and suggests that his requirement of gaplessness may seem off-putting to many of his contemporaries.

${ }^{18}$ Compare Frege's letter to Marty in Frege (1976), xxx/1, p. 163, and for discussion Heck (2012), ch. 1.

${ }^{19} \mathrm{He}$ seemed to have followed the advice from Carl Stumpf, who in a letter encouraged him to spell out his ideas in a more accessible manner. See Frege (1976), XL, p. 257. 
idea or intuition of it?" (Grundlagen, \$62). The curious twist in the history of Abstractionism is that Frege rejects the attempt to answer the question by appeal to Hume's Principle.

Frege explores addressing the epistemic challenge he poses at the beginning of $\$ 62$ by appeal to the context principle: only in the context of a sentence do words have meaning. ${ }^{20}$ According Frege, then, to account for our knowledge of numbers we have to explain the content of a sentence in which the number word occurs, in particular, we require a general criterion that allows us to recognise some object $a$ as the same again. Frege's proposal is to use Hume's Principle, which fixes the truth-conditions of identity statements involving the concept CARDINAL NUMBER. ${ }^{21}$

It is exactly this basic proposal in which semantic and epistemic Abstractionism take their origin. The story, however, does not quite end here for Frege: in the subsequent sections, he discusses three criticisms against the use of Hume's Principle qua abstraction principle to account for our grasp of numbers. He rejects the first two challenges, and then presents what is now known as the Caesar Problem. Having considered the abstraction principle for directions, $\mathrm{AP}_{d}$ instead of $\mathrm{HP}$ in most of his discussion, Frege presents the following challenge in $\$ 66$ :

In the proposition,

"the direction of $a$ is identical with the direction of $b$ "

the direction of $a$ appears as object, and our definition affords us a means of recognizing this object as the same again, in case it should happen to appear in some other guise, say as the direction of $b$. But this means does not suffice for all cases. One cannot, for instance, decide on its basis whether England is the same as the direction of the Earth's axis. Please forgive the example which seems nonsensical! Of course, no one will confuse England with the direction of the Earth's axis; but that is no thanks to our explanation. It says nothing as to whether the proposition

$$
\text { "the direction of } a \text { is identical with } q \text { " }
$$

should be affirmed or denied, unless $q$ is given in the form of 'the direction of $b$ '. What we lack is the concept of direction [...].

(Frege, 1884, pp. 77-78)

The challenge is structurally similar to one raised in $\$ 56$. Here, Frege’s example does not involve the direction of the Earth's axis and England, but rather concerns the question whether Julius Caesar is a number-hence the

20 "Nur im Zusammenhange eines Satzes bedeuten die Wörter etwas." We here follow Austin and use "meaning" to render the German "Bedeutung" given that Frege is yet to draw his famous sense-reference distinction.

${ }^{21}$ Frege does not use the term "Hume's Principle", but he does refer to a passage in Hume's Treatise (as quoted by Baumann (1869, p. 565), (Frege, 1884, p. 78)). The original reads as follows: "We are in the possest of a precise standard, by which we can judge of the equality and proportion of numbers; and according as they correspond or not to that standard, we determine their relations, without any possibility of error. When two numbers are so combined, as that the one has always an unite answering to every unite of the other, we pronounce them equal'; and 'tis for want of such a standard of equality in extension, that geometry can scarce be esteem'd a perfect and infallible science." (Hume, 1739/1987, book I, part III, section I, p. 71) 
“Abstractionism_OUP_for_copyediting” - 2016/4/20 - 11:40 - page 8 - \#17

label "Caesar Problem". ${ }^{22}$ More generally, abstraction principles do not settle truth-conditions of mixed identity statements of the form:

$$
\S(\alpha)=t
$$

where $t$ is not of the form $\S(\beta)$.

Frege rejects Hume's Principle as an adequate foundation for his logicist project for this reason, the Caesar Problem, and instead turns to an explicit definition of cardinal numbers as extensions. On the basis of this explicit definition, he then proceeds to derive Hume's Principle as a theorem, and using it and other presumed laws of logic and further explicit definitions, he offers proof sketches of numerous familiar laws of arithmetic. ${ }^{23}$

Unfortunately, Frege says preciously little about extensions-in fact, he simply presupposes that the reader knows what extensions are and even considers them ultimately superfluous for his logicism. In a tantalizing footnote in $\$ 68$ he writes: ${ }^{24}$

I believe that one could say instead of "extension of the concept' simply "concept". [...] I presuppose that one knows what the extension of a concept is.

Given the lack of gapless proofs to establish the laws of number and the lack of support for his notion of extension, Frege provides a somewhat cautiously optimistic summary of his achievement in Grundlagen in $\$ 90$ :

I do not claim to have made the analytic character of arithmetical propositions more than probable, since one may still doubt whether the proofs can be conducted solely from purely logical laws, whether somewhere an unacknowledged premise of a different kind is involved. Also, the concern is not sufficiently addressed by the indications I have given of the proofs of some of the propositions [...]. (Frege, 1884, p. 102)

So it was the goal of his magnum opus, Grundgesetze der Arithmetik, to establish beyond doubt what according to Grundlagen is a probable account of arithmetic by providing gapless proofs and by stating explicitly the basic laws and explicit definitions required for these proofs. It is here that we encounter the second twist in the Abstractionist history.

In Grundgesetze, Frege offers six basic laws and here presents an abstraction principle as one of the basic laws of his formal system. Having previously shown Hume's Principle to be inadequate as a definition for the concept CARDINAL NUMBER, Basic Law V takes that very same form by fixing the

22 "[W]e can never, to take a crude example, decide by means of our definitions whether any concept has the number Julius Caesar belonging to it, whether this familiar conqueror of Gaul is a number or not." (Frege, 1884, p. 68)

${ }^{23}$ For example, Frege provides definitions of zero, natural numbers, and successor. However, as shown by Boolos and Heck (1998), Frege's sketch in $\$ \$ \$ 82-83$ of the existence of the successor, having previously established its uniqueness, is confused and ultimately unsuccessful. This situation is remedied in Grundgesetze where Frege offers a correct proof. See also Heck (2011a, ch. 3).

${ }^{24}$ Compare here also $\$ 107$, where Frege suggests that drawing on extensions of concepts is not, ultimately, of great importance for his logicism. These are puzzling remarks that are still debated in current Frege scholarship. 
identity-conditions for value-ranges by means of co-extensionality as the relevant equivalence relation. It is clear that Frege did not regard Basic Law V as a definition-he says so explicitly in the second volume of Grundgesetze ( $\$ 146$, p. 148, fn. 1)-and so he did not change his mind as to the force of the Caesar Problem; but given this, it is equally clear that the concept value-range is either still presupposed as known or based on something different. ${ }^{25}$

What exactly the philosophical role of Basic Law V in Grundgesetze isthat is whether Frege himself should be regarded as a semantic or even epistemic abstractionist-is itself part of a lively debate in Frege scholarship. Without doubt, however, Frege was a mathematical abstractionist: abstraction principles play a crucial part in the formal system that Frege presents. Part II of Grundgesetze shows step by step, in a manner exemplifying the ideal of gapless proofs, how we can, taking an abstraction principle as a basic law of logic, arrive at arithmetic.

However, as is well known, Frege's logicist project failed: Basic Law V is inconsistent in the system of Frege's Grundgesetze. In the Afterword to volume II of Grundgesetze, Frege gives an account of the antinomy reformulated in his formal system and then offers a fix-replacing Basic Law V by so-called $\mathrm{V}^{\prime}$ :

$$
\dot{\varepsilon} f(\varepsilon)=\dot{\varepsilon} g(\varepsilon) \leftrightarrow \forall x(x=\dot{\varepsilon} f(\varepsilon) \vee x=\dot{\varepsilon} g(\varepsilon) \vee f(x)=g(x))
$$

For the special case of extensions, $\mathrm{V}^{\prime}$ states that the extensions of two concepts are the same if and only if the same objects fall under these concepts, with the possible exception of these extensions themselves (Frege, 1903, vol. II, p. 262).

We may assume that Frege later realised that this would not suffice since he never published further work based on $\mathrm{V}^{\prime}$. Indeed, $\mathrm{V}^{\prime}$ is inconsistent with the assumption that there are at least two distinct objects. ${ }^{26}$ More intriguingly, Frege seems to think that the paradox does not merely concern Basic Law V but also affects the status of abstraction principles in general. In a letter to Russell, Frege considers other abstraction principles but concludes that "the difficulties here, however, are the same as with the transformation of a generality of an equality in a value-range equality." 27 So, it seems that ultimately

\footnotetext{
${ }^{25}$ Frege does consider a version of the Caesar Problem in $\$ 10$ of volume I. How this fits into a broader interpretation of Frege's philosophy is another big issue in Frege scholarship. For an extremely insightful discussion of the role of the Caesar Problem in Frege's mature theory, see Heck (2011a) and (Heck, 2012, part I).

${ }^{26}$ In fact, $\mathrm{V}^{\prime}$ is arguably inconsistent in the system of Grundgesetze, because that system entails the existence of two objects: the True and the False. See the thorough investigation in Cook (forthcoming). Leśniewiski was apparently the first person to discover the inconsistency of $\mathrm{V}^{\prime}$ with the assumption that there are at least two objects (reported by Sobociński (1949-1950, 1984), (IV). The result was popularised by Quine (1955). Linsky and Schumm (1971) seem to have been the first to explicitly recognise the one element model of V'. See also Geach (1956), Dummett (1973), Linsky and Schumm (1973), Klement (2002, pp. 56-57), Landini (2006), Landini (2012, ch. 6), and Heck (2012, ch.4).

${ }^{27}$ Frege (1902), p. 224; the English translation in Gabriel et al. (1980, p 141) erroneously inserts a "not" between "are" and "the same".
} 
“Abstractionism_OUP_for_copyediting” - 2016/4/20 - 11:40 - page 10 - \#19

Frege not only gave up on his logicism but also had more general misgivings about the prospect of Abstractionism as a whole. ${ }^{28}$

\subsection{ABSTRACTIONISM AND NEO-FREGEANISM}

Wright's defense of neo-Fregeanism in Frege's Conception of Numbers as $\mathrm{Ob}$ jects (1983) triggered a revival of Abstractionism. Wright defends versions of semantic, epistemic, and ontological Abstractionism and came to regard Hume's Principle as the main foundational principle for our grasp of the concept CARDINAL NUMBER, our knowledge of arithmetic, and our knowledge of numbers as objects. Shortly after the publication, Wright was joined by Bob Hale (1987) as another proponent of neo-Fregeanism. Neo-Fregeanism so understood adopts Frege's assumption of classical (higher-order) logic. Neil Tennant (1987), on the other hand, provided a detailed formal derivations of the Peano-Dedekind axioms within a free intuitionistic relevant logic, and has since developed a view called constructive logicism (see also Tennant (2009)). A further distinct form of neo-logicism inspired by Frege's Grundgesetze is Edward Zalta's defense of modal logicism (Zalta, 1999). ${ }^{29}$ In general, there are now various position that adopt the label "neo-logicism" and take Hume's Principle (or a suitable version thereof) as a foundation of natural number arithmetic. $^{30} \mathrm{We}$ are not able to provide a survey of the different forms of neo-logicism here (see however the survey in Tennant (2014)), much less assess them. Rather, we focus mainly on Hale and Wright's version of NeoFregeanism which was defended in numerous articles and books since $1983 .^{31}$ Naturally, the various philosophical concerns raised in the context of Hale and Wright's conception may also be raised with regards to other forms of logicism. We hope that future research will help to establish how well other forms of neo-logicism fare with respect to them, and how the different positions compare. ${ }^{32}$

At bottom, the possibility of this revival of logicism is based on the discovery of Frege's Theorem by Wright (1983, pp. 158-169). In what follows,

${ }^{28}$ See here also Blanchette (2016). Also note that $\mathrm{V}^{\prime}$ is itself already problematic if viewed as an abstraction principle: there are occurrences of the value-range operator on the right-hand side of the abstraction principle, and so the explanandum appears in the explanans.

${ }^{29}$ See also Linsky and Zalta (1995), Zalta (2000); moreover, see Anderson and Zalta (2004) for a different approach.

${ }^{30}$ For further examples of broadly (neo-)logicist approaches to arithmetic, see Antonelli and May (2005), Boccuni (2010, 2013), Bostock (1974-79), Demopoulos (1998, 2000), Fine (2002), Heck (1997a, 2011a), Hodes (1984), Linnebo (forthcoming), Rayo (2002, 2005, 2013, ch.3-4), Urbaniak (2010), and Wehmeier (1999), amongst many others.

${ }^{31}$ Most notably in Wright (1983), Hale (1987), and Hale and Wright (2000).

${ }^{32}$ The beginnings of such a debate may be found in Linsky and Zalta (2006), Ebert and Rossberg (2006), Ebert and Rossberg (2009), and Zalta (2009). 
we swiftly outline some of the main results of mathematical Abstractionism to provide a technical background for this volume. ${ }^{33}$

A fully rigorous proof of Frege's Theorem in a classical setting was first presented by Boolos (1990); see also the detailed exposition and discussion in Heck (2011a). ${ }^{34}$ Heck (1997a) has since shown that an abstraction principle weaker than Hume's Principle suffices for the foundation of natural number arithmetic: so-called Finite Hume, a version of Hume's Principle in which the range of the second-order variables is restricted to finite concepts. Frege Arithmetic-i.e., the second-order logic plus Hume's Principle-was shown to be equiconsistent with second-order arithmetic by Boolos (1987)-the model Boolos provides for Hume's Principle was previously hinted at by Geach (1976); see also the (independent) results by Hodes (1984), Burgess (1984), and Hazen (1985).

The success of mathematical Abstractionism is not restricted to capturing natural number arithmetic, however. Much work has gone into investigating the viability of abstractionist foundations for other areas of mathematics. A first step is to extend the abstractionist treatment to real analysis, while a more ambitious goal is providing an abstractionist set theory strong enough to yield Zermelo-Fraenkel set theory.

An approach to analysis inspired by Richard Dedekind's construction of the reals ${ }^{35}$ was developed by Stewart Shapiro (2000) (see also Wright (2000)), through step-wise abstraction of integers, rationals, and real numbers. We start with an abstraction principle for ordered pairs, $\langle a, b\rangle$ :

$$
\langle a, b\rangle=\langle c, d\rangle \leftrightarrow(a=c \wedge b=d)
$$

Ordered pairs of natural numbers (provided by Hume's Principle) can then be utilized to define integers. This proceeds via an abstraction principle for differences:

$$
\operatorname{Diff}\langle a, b\rangle=\operatorname{Diff}\langle c, d\rangle \leftrightarrow(a+d=b+c)
$$

Integers can be identified with these difference. Since we are working in secondorder logic, addition and multiplication for integers can be explicitly defined. The next step is an abstraction principle for quotients, using the defined integers and multiplication:

$\mathrm{Q}\langle m, n\rangle=\mathrm{Q}\langle p, q\rangle \leftrightarrow((n=0 \wedge q=0) \vee(n \neq 0 \wedge q \neq 0 \wedge m \times q=n \times p))$

Rational numbers are then identified with quotients $\mathrm{Q}\langle m, n\rangle$, where $n \neq 0$. Defining again addition and multiplication, this time for the rationals, and

${ }^{33}$ Cook (2007) collects a number of important essays on the mathematics of abstraction.

${ }^{34}$ As we noted above Tennant (1987) offers a detailed proof using a free intuitionistic relevant logic. See also Bell (1999) for a discussion of Hume's Principle in a constructive setting. Shapiro and Linnebo (2015) show that Hume's Principle embedded in intuitionistic logic yields Heyting Arithmetic.

${ }^{35}$ Dedekind (1872); regarding the question to what extent Dedekind himself was a logicist see Demopoulos and Clark (2005), Reck (2013), Reck (forthcoming), Yap (forthcoming); see also Tait (1996). 
also defining the natural less than-relation, we use a final abstraction principle, called Cut Abstraction:

$$
\operatorname{Cut}(P)=\operatorname{Cut}(Q) \leftrightarrow \forall r(P \leq r \leftrightarrow Q \leq r)
$$

' $P \leq r$ ' holds for a concept $P$ (applying to rationals) and a rational $r$ if and only if every rational that is $P$ is less than or equal to $r$. We can now identify real numbers as those cuts $\operatorname{Cut}(P)$ where the rationals falling under $P$ are bounded above.

The procedure above yields uncountably many reals that form an ordered field that has the least-upper-bound property, as required for the real numbers. This approach has a decidedly structural feel however. A more object-oriented approach was in fact the first proposal for an abstractionist foundation of real analysis. It is due to Bob Hale (2000b), and arguably more Fregean in character (Wright (2000), Hale and Wright $(2005, \$ 6))$. Hale proposes a first-order abstraction principle that abstracts reals directly from pairs of quantities:

$$
\mathrm{R}\langle a, b\rangle=\mathrm{R}\langle c, d\rangle \leftrightarrow \mathrm{E}(\langle a, b\rangle,\langle c, d\rangle)
$$

where $\mathrm{E}$ is an equivalence relation on pairs of quantities. While more Fregean in spirit, this approach has open questions regarding the nature of quantities and the possibility of a purely logical definition of the required equivalence relation E. Moreover, further research needs to establish whether the resulting theory can yield a sufficiently large ontology-that is, a continuum-and can thus interpret real analysis.

As mentioned above, the ambitious aim is an abstractionist foundation of set theory. ${ }^{36}$ The abstraction principle that might have seemed promising for a foundation of set theory is, of course, Basic Law V. As explained earlier (see footnote 2 above), if we restrict the range to concepts, rather than all functions, Basic Law V states that two concepts have the same extension if and only if they are co-extensional:

$$
\grave{\varepsilon} F \varepsilon=\dot{\varepsilon} G \varepsilon \leftrightarrow \forall x(F x \leftrightarrow G x)
$$

Extensions of concepts would be sufficiently similar to classes ${ }^{37}$ to underwrite set theory. Alas, Basic Law V provides a wee bit too much in Frege's system.

Frege's first instinct was to restrict Basic Law $\mathrm{V}$ in order to avoid the inconsistency, but as already mentioned $(\$ 1.2)$, he did not go about it in the

\footnotetext{
${ }^{36}$ For assessments of the prospects of an abstractions set theory see, for instance, Clark (1993), Shapiro and Weir (1999), Hale (2000a), Cook (2003a), Shapiro (2003), Linnebo and Uzquiano (2009), Cook (2016).

${ }^{37}$ In the second volume of Grundgesetze (1903), $\$ 147$, Frege concurs: "When logicians have long spoken of the extension of a concept and mathematicians have spoken of sets, classes, and manifolds, then such a conversion forms the basis of this too; for, one may well take it that what mathematicians call a set, etc., is really nothing but the extension of a concept, even if they are not always clearly aware of this."
} 
right way. George Boolos (1989) also proposes a restriction of Basic Law V, but bases it on the limitation-of-size approach to set theory. ${ }^{38}$ The abstraction principle Boolos proposes states that two concepts have the same extension if and only if they are co-extensional unless the concepts are "too big". Concepts are consider to be too big just in case they are the same size as the universe. The latter property is expressible in second-order logic again: as a one-to-one correspondence with the concept of self-identity. If we call this property 'Big', Boolos's abstraction principle for extensions reads like this:

$$
\operatorname{Ext}(F)=\operatorname{Ext}(G) \leftrightarrow((\operatorname{Big}(F) \wedge \operatorname{Big}(G)) \vee \forall x(F x \leftrightarrow G x)) \quad(\text { New V) }
$$

We may define a set to be the extension of a concepts unless the concept is big:

$$
\operatorname{Set}(x)=_{\mathrm{df}} \exists F(x=\operatorname{ExT}(F) \wedge \neg \operatorname{Big}(F))
$$

and define membership for extensions as:

$$
x \in y=\mathrm{df} \exists F(F x \wedge y=\operatorname{ExT}(F))
$$

Restricted to sets thus defined, the second-order theory containing New V proves the ZF principles of extensionality, empty set, pairing, separation, and replacement, but not union. The extension of Big concepts, call it "Bad", is still an object in the theory, but Bad cannot be a set on pain of inconsistency. The union of the singleton set containing Bad, however, would have to be a set whose members are all the elements of Bad, which cannot be. New V thus in fact entails the negation of union. We can, however, reformulate union: instead of saying that the union of a set $S$ is the set containing all and only those objects that are members of members of $S$, we restrict the definiens by stipulating that the union of $S$ be the set containing all and only those elements that are members of the sets that are members of $S$ (thus excluding the members of Bad, should Bad be a member of $S$ ). Formally:

$$
\begin{aligned}
\forall x[\operatorname{Set}(x) \rightarrow & \exists y(\operatorname{Set}(y) \wedge \\
& \forall z[z \in y \leftrightarrow \exists w(\operatorname{Set}(w) \wedge(z \in w \wedge w \in x))])]
\end{aligned}
$$

(Union*)

The occurrence of 'Set(w)' expresses the restriction to members that are sets explained above. Note that with this restriction in place, the union* of the singleton of Bad is the empty set. New V entails union*.

New V does not, however, entail infinity, power set, or foundation. Of these, foundation alone can be recaptured if we further restrict the scope of sets taken into account. The obvious restriction is to pure sets-those that can

\footnotetext{
${ }^{38}$ See Hallett (1984) for a careful and thorough study of the limitation-of-size conception of set and a comparison with the iterative conception.
} 
“Abstractionism_OUP_for_copyediting” - 2016/4/20 - 11:40 - page 14 - \#23

be "build up" from the empty set, as it were. Let a concept $F$ be closed exactly when all sets, all of whose members are $F$, are also $F$ :

$$
\operatorname{Closed}(F) \leftrightarrow_{\mathrm{df}} \forall y((\operatorname{Set}(y) \wedge \forall z(z \in y \rightarrow F z)) \rightarrow F y)
$$

We can define the pure sets as those objects that fall under all closed concepts: ${ }^{39}$

$$
\operatorname{Pure}(x) \leftrightarrow_{\mathrm{df}} \forall F(\operatorname{Closed}(F) \rightarrow F x)
$$

New $\mathrm{V}$ proves that foundation holds for pure sets. ${ }^{40}$

While the set theory gained from New V certainly is to be booked as a considerable success, it still falls short of full ZF set theory. Roy Cook (2003b) sets out to remedy the shortcoming. Cook aims for a set theory based on abstraction principles that captures the iterative conception of set. His starting point is an abstraction principle for ordinals, the Size-Restricted Ordinal Abstraction Principle, SOAP. To get there, consider the obvious, but owing to the the Burali-Forti Paradox inconsistent, Order-Type Abstraction Principle:

$$
\mathrm{OT}(R)=\mathrm{OT}(S) \leftrightarrow R \cong S
$$

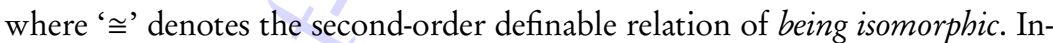
troducing a restriction to relations that are well-ordered ${ }^{41}$ (WO) and whose field is not Big (analogous to the way 'Big' is defined above), we may arrive at the consistent Size-Restricted Ordinal Abstraction Principle:

$$
\begin{aligned}
& \mathrm{ORD}(R)=\operatorname{ORD}(S) \leftrightarrow \\
& {[((\neg \mathrm{WO}(R) \vee \operatorname{Big}(R)) \wedge(\neg \mathrm{WO}(S) \vee \operatorname{Big}(S))) \vee} \\
& (\mathrm{WO}(R) \wedge \mathrm{WO}(S) \wedge \neg \operatorname{Big}(R) \wedge \neg \operatorname{Big}(S) \wedge R \cong S)]
\end{aligned}
$$

The abstracta provided by SOAP are used to enumerate the stages in the "construction" of the iterative hierarchy. Moreover, SOAP is satisfiable on all and only infinite domains.

It follows the definition of 'being at the stage of (ordinal) $\alpha$ '. The formal definition is omitted here for the sake of brevity, but, roughly, there will be a base stage, which consists of elements of a chosen basis (if any), and each subsequent stage will contain that basis as well as all those extensions that only contain objects from prior stages. Let 'Bad' be true of a concept if there is no well-ordered ordinal $\alpha$ such that all object falling under that concept are

\footnotetext{
${ }^{39}$ The rationale, roughly, is that the empty set, not having any members, has to fall under every closed concept; hence, so does its singleton; hence, so do the sets that contain only one or both of these, and so on. See also Boolos (1989), Theorems 1 and 2, for the adequacy of the definition.

${ }^{40} \mathrm{New} \mathrm{V}$ also proves that foundation holds for hereditary sets (in the usual sense). All pure sets (in the sense defined above) are hereditary, but not vice versa. For an extensive study of non-pure hereditary sets in the context of New V set theory see Jané and Uzquiano (2004).

${ }^{41}$ Well-ordered in the usual sense, which is second-order definable; see Shapiro (1991, p. 106), Cook (2003b, \$4)
} 
at the stage of $\alpha$. With these notions in hand, we can formulate the abstraction principle Newer $V$ :

$$
\operatorname{Ext}(F)=\operatorname{Ext}(G) \leftrightarrow[\forall x(F x \leftrightarrow G x) \vee(\operatorname{Bad}(F) \wedge \operatorname{Bad}(G))] \quad(\text { Newer } \mathrm{V})
$$

Even in this informal presentation, the reader will have noticed a circularity: Newer $\mathrm{V}$ introduces extensions, using "being at the stage of $\alpha$ ", on the right-hand-side of the abstraction principle; but extensions feature in the definiens of "being at the stage of $\alpha$ ". Cook $(2003 \mathrm{~b}, \$ 5)$ shows that there are equivalent recursive formulations available, which, if metaphors are permissible, also highlight the mutual "seesawing up" of ordinal stages and extensions in an imagined step-wise construction: the ordinal stages form a spine for the hierarchy of extensions, but more extensions also allow adding more ordinal stages, which, in turn, allows the hierarchy of extensions to be built up further, and so on, indefinitely.

'Set' and ' $\epsilon$ ' can be defined as for New V above. Restricting the relevant quantifiers to sets, Newer $\mathrm{V}$ entails extensionality, empty set, pairing, separation, union* (but not union), and powerset. Restricting further to pure sets, we can prove foundation, just like in the case of New V; also union holds for pure sets. ${ }^{42}$

SOAP plus Newer V does not entail replacement, and despite SOAP only having infinite models, SOAP plus Newer V does not in general entail infinity (i.e., the existence of an infinite set). They do, however, together with an "axiom of infinity", i.e., the claim that the basis (as mentioned above) contains all finite well-ordered ordinals. ${ }^{43}$

Neither New V (expressing the abstractionist limitation-of-size conception of set), nor SOAP plus Newer V (expressing the abstractionist iterative conception of set) thus provides a set theory as strong as (second-order) ZF. The situation changes, if we adopt both New V and Newer V in tandem. First, however, note the divergence from the original abstractionist claim, according to which terms for abstract are implicitly defined by a single abstraction principle. We might be able to finess the situation regarding New V and Newer V. If Finite Hume and Hume's Principle are about the same abstract objects (as one might not implausibly argue), then perhaps New $\mathrm{V}$ and Newer $\mathrm{V}$ can govern the extension-operator in concert. (See the discussions by Fine (2002, esp. p. 49) and Cook (2003b, \$9).)

Setting this discussion aside, the technical results are as follows: the secondorder theory containing all three abstraction principles, New V, Newer V, and SOAP, ${ }^{44}$ is consistent, and with the definitions of 'Set' and ' $\in$ ' as above,

\footnotetext{
${ }^{42}$ Union also holds for hereditary sets (see fn. 40 above), but foundation does not.

${ }^{43}$ Let us call the non-sets urelemente. It is tempting to think of the basis as the collection of urelemente, but there is in fact no guarantee that it contains all or even only urelemente.

${ }^{44}$ Interestingly, in this setting, SOAP can be dispensed with: instead of the ordinals provided by SOAP, the stages can be ordered according to the more "conventional" ordinals (transitive pure sets, well-ordered by ' $\epsilon$ ') supplied by New V, but some complicating adjustments in New V and Newer V are required; see Cook (2003b, p. 90, n. 30).
} 
“Abstractionism_OUP_for_copyediting” - 2016/4/20 - 11:40 - page 16 - \#25

it proves that 'Big' and 'Bad' are co-extensional and that all non-sets (or urelemente) are in the basis. ${ }^{45}$ Moreover, we capture all $\mathrm{ZF}$ axioms except foundation and infinity. If we assume, in addition, that there are infinitely many non-sets we can prove infinity (thanks to the fact that all urelemente are now in the basis). Note that obtaining infinitely many non-sets may be straightforward for the abstractionist, if the cardinal numbers governed by, say, Finite Hume, ${ }^{46}$ are not identical to extensions-that is, if we can suppose a favorable solution regarding the question of the identity of abstracta governed by different abstraction principles (Cook (2003b, \$10); see also Fine (2002), Cook and Ebert (2005), Mancosu (2015b)). Moreover, once again, foundation holds for pure sets. With theses caveats, full second-order ZF is recaptured by way of abstraction.

Mathematical Abstractionism has been developed in a variety of other directions, exploring further aspects of abstractionist mathematics and extending its reach. For instance (with no claim to completeness), Graham LeachKrouse (2015) investigates structural abstraction principles; Shay Logan (2015, 2016) presents abstractionist foundations for category theory; Morgan Thomas (ms) proposes a single third-order abstraction principle on isomorphisms as an approach to set theory; Stewart Shapiro and Geoffrey Hellman (2016) investigate an abstraction principle for points in a point-free geometry; James Studd (forthcoming) proposes a dynamic approach to abstraction.

These advances in the mathematics of abstraction, of course, do not by themselves answer the philosophical questions that arise for Abstractionism, and indeed they raise further philosophical problems. In the following two sections, we turn our attention to philosophical and mathematical challenges for Abstractionism-and with that to the contents of this volume.

\subsection{PHILOSOPHICAL ABSTRACTIONISM: CHALLENGES}

This volume is structured to reflect the main themes of Abstractionism. Part II deals with the semantic and ontological issues surrounding Abstractionism, while Part III focuses mainly on the epistemic aspects of Abstractionism.

As discussed above, Frege briefly considered Hume's Principle as an explanation of number-terms, but rejected it because of the Caesar Problem. An Abstractionist account of arithmetic that goes back to taking Hume's Principle as a fundamental principle meets the problem again. In the first essay of Part II, "Caesar and Circularity", William Stirton presents a critical investigation of the solution to the Caesar Problem proposed in Hale and Wright (2001b).

Another challenge Abstractionism faces has been dubbed the Proliferation Problem (Heck, 2000). Abstractionism appears to make it too easy to refer to

\footnotetext{
${ }^{45}$ Compare footnote 43 above.

${ }^{46}$ Alas, full Hume's Principle is inconsistent with this abstractionist set theory, see Cook (2003b, p. 90, n. 33).
} 
abstract objects. Any equivalence relation could in principle do as the righthand side of an abstraction principle, no matter how gerrymandered it may be, or how unusual the resulting abstracta are. Critics object that this leads to an undue proliferation of abstract objects. Richard Heck develops this criticism in "The Existence (and Non-Existence) of Abstract Objects" and presents a solution that gives rise to an account of what it is for abstract objects to exist.

A debate concerning the metaontology of abstractionist accounts of mathematics has recently arisen in light of different interpretations of what Wright (1983) calls the syntactic priority thesis: singular terms occurring in true atomic sentences are guaranteed to have a referent-i.e., an object is guaranteed to exist for the term to pick out. On that basis then, number-terms, assuming they are singular terms, will be guaranteed to pick out numbers as objects provided that Hume's Principle is true. This, however, seems somewhat too easy to establish platonism, and critics have argued that abstraction principles appear to stipulate abstract objects into existence, and that Abstractionism hence is incompatible with a broadly platonist philosophy of mathematics. ${ }^{47}$

Matti Eklund subjects the ontology of Abstractionism to such a metaontological investigation in "Hale and Wright on the Metaontology of NeoFregeanism". He contrasts maximalism, which he argues follows from Hale and Wright's reliance the syntactic priority thesis and which, roughly, holds that everything that can exist, does exist-a "maximally promiscuous ontology"-with other metaontological doctrines including a minimalism endorsed by Hale and Wright themselves.

Fraser MacBride, in "Neo-Fregean Ontology: Just Don't Ask Too Many Questions", investigates the syntactic priority thesis directly. He presents a dilemma for the abstractionist: if reality is crystalline, possessing a languageindependent structure, then the thesis is "hostage to cosmological fortune"; if, on the other hand, reality has plasticity, this seems to be in tension with the thought that statements about these objects are true of an independent reality. MacBride argues that ontological quietism is the only option for neo-Fregeans to meet the challenge: that is, neo-Fregeans need to argue that the question how language harmonises with reality can be rejected.

In the last chapter of Part II, "The Number of Planets, a Number-Referring Term?", Friederike Moltmann challenges the Fregean view that number terms, like 'the number of planets', refer to numbers as abstract object. Moltmann argues that on the contrary such natural-language expressions refer to number tropes, that is, properties instantiated in the plurality of objects that a given statement of number is about.

Part III opens with Philip Ebert's "A Framework for Implicit Definitions and the A Priori”. According to the view labeled traditional connection, which

\footnotetext{
${ }^{47}$ The origins of this debate can be found in Dummett (1981a,b, 1991); for a discussion of some of his criticisms, see for example Wright (1998a,b), Hale (1994b), MacBride (2003), and Ebert (2015). For the more recent metaontological debate see Eklund (2006), Hawley (2007), Sider (2007), and Hale and Wright (2009).
} 
“Abstractionism_OUP_for_copyediting” - 2016/4/20 - 11:40 - page 18 - \#27

at least for some time was held by Hale and Wright, abstraction principles are regarded as a special kind of implicit definitions of the mathematical terms. Hume's Principle, for instance, would be seen as an implicit definition of the concept CARDINAL NUMBER and offers an a priori foundation for classical mathematics. Ebert present a general framework for implicit definitions, identifies the main tenets for this view, and highlights the main challenges it faces.

A new approach to the understanding of the epistemic foundation of abstraction principles employs Wright's notion of entitlement, a type of defeasible, non-evidential warrant for presuppositions of particular cognitive projects. In "Abstraction and Epistemic Entitlement: On the Epistemological Status of Hume's Principle”, Crispin Wright argues that Hume's Principle enjoys the status of an entitlement. Wright argues that the a priori status of our arithmetical knowledge can be secured in this way.

In the next chapter, "Hume's Principle and Entitlement", Nikolaj Pedersen takes up the same topic. He investigates the notion of entitlement within the setting of Abstractionism and asks, inter alia, whether entitlements are indeed defeasible, as Wright suggests. Further, Pedersen raises a concern he labels "Generosity Problem": entitlements, he suggests, may seem too easy to come by, so that a wide range of irrational and bizarre projects would appear to have entitlements as their basis. He suggests that a proper assessment of the Generosity Problem highlights the inherent relativity of entitlements.

Part III closes with Agustín Rayo's “Neo-Fregeanism Reconsidered”. Rayo presents a platonist account of mathematics that employs a primitive relation: the just is relation. Just is statements exhibits a tight connection to statements of metaphysically necessary equivalence. According to the account, for the number of the planets to be eight just is for there to be eight planets, for instance. Rayo argues that abstraction principles are best understood as just is statements of the kind he introduces in his more general account.

\subsection{MATHEMATICAL ABSTRACTIONISM: CHALLENGES}

Part IV of this collection focuses on aspects that chiefly concern mathematical Abstractionism. We start with the so-called Bad Company objection. ${ }^{48}$ All abstraction principles are biconditionals featuring statements of identity of abstracta of a certain type on one side, and the specification of an equivalence relation on the other. Hume's Principle is the abstractionists' poster child. It gives rise to arithmetic. On the other end, we have Basic Law V-which gives rise to Russell's Paradox. But how do we tell the "good" abstraction principles, like Hume's Principle, from the "bad" ones, like Basic Law V, when their logical form is fundamentally the same? Requiring that an abstraction principle

\footnotetext{
${ }^{48}$ Bad Company concerns were first raised by Neil Tennant (1987, p. 236) and George Boolos (1987, p. 184); see the discussion in Tennant $(2014, \$ 1.2 .3)$. The more recent discussion takes wing from Dummett (1991, pp. 188-189), Wright (1998a), Dummett (1998), and Wright (1998b). See also the articles in the special issue on Bad Company edited by Linnebo (2009).
} 
has to be consistent may seem ad hoc and unilluminating; moveover, importantly, it is not even sufficient.

First, there is the question of the underlying logic in which the consistency question is to be decided. Terence Parsons (1987) provides a consistency proof for the first-order fragment of Frege's system in Grundgesetze, including Basic Law V. Richard Heck (1996) shows that Basic Law V is consistent in predicative second-order logic. As Kai Wehmeier (1999) and Fernando Ferreira and Wehmeier (2002) show, Basic Law V is indeed consistent in a second-order logic with $\Delta_{1}^{1}$-comprehension. ${ }^{49}$

Second, even the restriction to abstraction principles that are individually consistent or perhaps satisfiable in full second-order logic will not suffice to demarcate the "good" from the "bad" abstraction principles. There are abstraction principles that are individually consistent, but not consistent with one another. Hume's Principle, for instance, is not jointly satisfiable with George Boolos's Parity Principle or Wright's Nuisance Principle.$^{50}$ Both of these abstraction principles require the domain to be finite, whereas Hume's Principle is only satisfiable on an infinite domain. Wright (1997) proposes that acceptable abstraction principles have to be conservative, in the sense that they should not put any constraints on any objects other than those abstracts that it introduces. Hume's Principle passes this test, but the Nuisance Principle does not: it does not only require that there are only finitely many nuisances, but indeed that there are only finitely many object in total-a violation of conservativeness. The Parity Principle is disqualified for the same reason. While conservativeness might be a necessary condition, it does not appear to be sufficient: Alan Weir (2003) produces a pair of abstraction principles each of which is conservative; however, they are not jointly satisfiable.

Roy Cook's contribution to this volume, "Conservativeness, Cardinality, and Bad Company", systematizes the discussion. Cook rigorously formulates

\footnotetext{
${ }^{49}$ Wehmeier (1999) and Ferreira and Wehmeier (2002) investigate different $\Delta_{1}^{1}$ theories, as explained in the latter publication. Restrictions on the second-order comprehension schema in effect regulate how much impredicativity is allowed in the definition of predicates. This is achieved by considering formulae in the pre-fix normal form. If, and only if, the formula in question is logically equivalent to a formula that features only pre-fix universal second-order quantifiers, and no other second-order quantifiers, we call the formula $\Pi_{1}^{1}$. Analogously, we call a formula is $\Sigma_{1}^{1}$ if, and only if, it is equivalent to a formula that features only pre-fix existential second-order quantifiers, and no others. (Note that the block of pre-fixed quantifiers must not be interrupted by negations.) A formula that is equivalent to both a $\Pi_{1}^{1}$ and a $\Sigma_{1}^{1}$ formula is called $\Delta_{1}^{1}$. Accordingly, in second-order logic with $\Delta_{1}^{1}$-comprehension the comprehension schema is restricted to instances where the defining open sentence is $\Delta_{1}^{1}$.

Both $\Sigma_{1}^{1}$ - and $\Pi_{1}^{1}$-comprehension are inconsistent with Basic Law V, so, in that sense, $\Delta_{1}^{1}$ is the highest complexity we can allow in the presence of Basic Law V.

See also Fine (2002), Linnebo (2004), Burgess (2005), Visser (2009), Antonelli (2010), Heck (2011a, ch. 12), Heck (2011b, 2014), Walsh (2012, 2014, 2015, 2016), and Walsh and Ebels-Duggan (2015), for further technical results in this area.

${ }^{50}$ Boolos (1990), Wright (1997); given modest assumptions about infinite concepts, the Nuisance Principle can indeed be shown to be (proof-theoretically) inconsistent with Hume's Principle; see Ebels-Duggan (2015)
} 
“Abstractionism_OUP_for_copyediting” - 2016/4/20 - 11:40 - page 20 - \#29

several proposed criteria for acceptable abstraction principles and presents an ordering of these criteria by relative strength. ${ }^{51}$ Moreover, he argues that the correct criterion for acceptable abstraction principles is strong stability. ${ }^{52}$

Regarding the inconsistency of Frege's logic presented in his Basic Laws of Arithmetic, we have mentioned already that the principle that is usually considered to be the culprit, Basic Law V, is in fact consistent in weak fragments of second-order logic. Indeed, Dummett (1991) suggests that the impredicativity of the second-order quantifiers is to blame for the inconsistency, rather than Basic Law V. Øystein Linnebo's "Impredicativity in the Neo-Fregean Programme" revisits the debate about this question that takes centre-stage in the exchange between Boolos (1993) and Dummett (1994). Linnebo examines the role of impredicative reasoning required for neo-Fregean programme (both technically and philosophically), and distinguishes two types of impredicativity that are conflated by Dummett and others. Linnebo suggests that some restrictions of impredicativity may lead to fruitful abstractionist theories.

In "Abstraction Grounded", Hannes Leitgeb argues against the very approach to distinguish acceptable from unacceptable abstraction principles. Instead, he develops a groundedness condition for impredicative abstraction principles in analogy to Saul Kripke's theory of truth (Kripke, 1975). The proposal is that any abstraction principle with impredicative second-order variables is to be restricted to those of its instances that satisfy certain groundedness requirements.

As mentioned above, set theory is a big issue for Abstractionism. Much progress has been made, but there currently does not appear to be a contender for a single abstraction principle that on its own, embedded in some higherorder logic, gives rise to a theory that is capable of interpreting ZermeloFraenkel set theory without presupposing prior knowledge of set theory, in some sense. ${ }^{53}$ A single abstraction principle, viewed as an implicit definition of set, would be the abstractionists' ideal.

The assessment of the prospects for an abstractionist foundation for set theory is the topic that Stewart Shapiro and Gabriel Uzquiano tackle in their "Ineffability Within the Limits of Abstraction Alone". They present an abstractionbased set theory that allows capturing all of ordinary mathematics, except for Zermelo-Fraenkel set theory itself. In particular, they discuss the extent to which the thought that the iterative hierarchy, which is underlying standard set theory, is indefinitely extensible, or "ineffable" in some sense, is in tension with an abstractionist foundation.

Part V contains three contributions regarding Frege's application constraint,

\footnotetext{
${ }^{51}$ Cook draws on previous work in this area by Øystein Linnebo (2010) and himself, Cook (2012).

${ }^{52} \mathrm{An}$ abstraction principle $A$ is strongly stable if and only if there is a cardinal $\alpha$ such that, for any cardinal $\kappa, A$ is satisfiable by a model with cardinality $\kappa$ iff $\kappa \geq \alpha$.

${ }^{53}$ Compare Cook (2003b, p. 91 n. 41), regarding the "distraction" principles of Shapiro and Weir (1999) and Weir (2003).
} 
sometimes just called "Frege's Constraint". ${ }^{54}$ Frege held that a successful account of arithmetic, analysis, and so forth, should "present the ways in which arithmetic [etc.] is applied, even though the application itself is not its subject matter" (Frege, 2013, vol. II, \$159). The application of a mathematical theory should be in some way build into the abstraction principle that provides the foundation of this part of mathematics: counting all kinds of objects for natural-number arithmetic; measuring different kinds of magnitude for real analysis; etc.

In "On Frege's Application Constraint”, Paul McCallion investigates the motivation for the Frege's Constraint and relates his results to Benacerraf-type concerns for Abstractionism. Paul Benacerraf (1965) submitted that the existence of competing but equally successful reduction of the natural numbersthe prime example being Zermelo's versus von Neumann's reduction of cardinal numbers to sets-spells doom for a reductionist programme. McCallion takes this lead and asks whether an analogous problem of alternative, but on the face of it equally attractive abstractionists account of a given mathematical theory, may indeed be solved by appeal to the application constraint.

Peter Simons addresses the topic we dodged above by our casual use of "etc." after listing the relevant applications for arithmetic and real analysis. In "Applications of Complex Numbers and Quaternions", Simons investigates whether obvious applications for mathematical theories other than natural number arithmetic and real analysis can be identified. Simons looks at the cases of complex numbers and quaternions and their physical applications.

The application constraint was important for Frege, but the question may be raised whether a successful philosophy of mathematics must obey it, or indeed can do so in full generality. Bob Hale's contribution, "Definitions of Numbers and Their Applications", discusses the issue of this tight connection between definitions or explanations of fundamental mathematical notions and their applications that Frege demanded. He compares different definitions of natural and real numbers, some of which obey Frege's constraint and some of which do not. His discussion investigates whether Frege himself offered a satisfactory motivation for his constraint and whether there is any other justification of it available. Hale concludes with suggesting an alternative approach.

\subsection{ACKNOWLEDGMENTS}

We would like to thank first and foremost the contributors to this volume and Peter Momtchiloff at Oxford University Press, not least for his patience that was required while we were finalising this volume.

In 2000, Crispin Wright founded the Arché Research Centre and under its aegis Bob Hale and Crispin Wright led a dedicated research project into

\footnotetext{
${ }^{54}$ See Frege $(1903, \$ 159)$ for the original formulation of the requirement, and Dummett (1991, pp. 272ff) and Wright (2000) for discussion.
} 
“Abstractionism_OUP_for_copyediting” - 2016/4/20 - 11:40 - page 22 - \#31

the philosophical and mathematical prospects of Neo-Fregeanism. The centre brought together numerous researchers in the philosophy of mathematics many of whom have contributed to this volume. We would thus like to thank Crispin and Bob without whom there would not have been this flourishing and exciting research. We would also like to thank the AHRC, who provided much of the funding for the research centre. In particular, Philip Ebert would like to acknowledge a grant from the UK Arts and Humanities Research Council (AH/J00233X/1) which he held while editing of this volume.

We would like to thank Michael Hughes and Colin McCullough-Benner for converting numerous contributions to this volume into $\mathrm{IT}_{\mathrm{E}} \mathrm{X}$ format. Special thanks also go to Colin McCullough-Benner for his further assistance in typesetting the volume and to ...N.N.... who helped preparing the index.

Finally, many thanks go to ......, Rashed Ahmad, Roy Cook, ..... for helpful comments on an earlier draft of this introduction.

\section{REFERENCES}

Anderson, David J. and Edward N. Zalta (2004). 'Frege, Boolos, and Logical Objects', Journal of Philosophical Logic 33:1-26.

Antonelli, Aldo and Robert May (2005). 'Frege's Other Program', Notre Dame Journal of Formal Logic 46:1-17.

Antonelli, G. Aldo (2010). 'The Nature and Purpose of Numbers', Journal of Philosophy 107:191-212.

Baumann, Joh. Julius (1869). Die Lebren von Raum, Zeit und Mathematik in der neueren Philosophie: nach ibrem ganzen Einfluss dargestellt und beurteilt. Vol. 2: Leibniz, Leibniz und Clarke, Berkeley, Hume. Kurzer Lebrbegriff von Geometrie, Raum, Zeit und Zabl. Schluss und Regeln aus dem Ganzen. Berlin: Verlag von Georg Reimer.

Bell, John L. (1999). 'Frege's Theorem in a Constructive Setting', Journal of Symbolic Logic 64:486-488.

Benacerraf, Paul (1965). 'What Numbers Could Not Be', Philosophical Review 74:47-73.

Blanchette, Patricia (2012). Frege's Conception of Logic. Oxford: Oxford University Press.

(2016). 'The Breadth of the Paradox', Philosophia Mathematica forthcoming.

Boccuni, Francesca (2010). 'Plural Grundgesetze', Studia Logica 96:315-330. (2013). 'Plural Logicism', Erkenntnis 78:1051-1067.

Boolos, George (1987). 'The Consistency of Frege's Foundations of Arithmetic', in J. J. Thomson (ed.), On Being and Saying: Essays for Richard Cartwright. Cambridge, Mass.: The MIT Press, pages 3-20. Reprinted in Boolos (1998), pages 183-201. 
(1989). 'Iteration Again', Philosophical Topics 17:5-21. Reprinted in Boolos (1998), pages 88-104.

(1990). 'The Standard of Equality of Numbers', in George Boolos (ed.), Meaning and Method: Essays in Honor of Hilary Putnam. Cambridge: Cambridge University Press, pages 261-278. Reprinted in Boolos (1998), pages 202-219.

- (1993). 'Whence the Contradiction?', Proceedings of the Aristotelian Society, Supplementary Volume 67:213-233. Reprinted in Boolos (1998), pages 220-236.

(1997). 'Is Hume's Principle Analytic?', in Heck (1997b), pages 245-

262. Reprinted in Boolos (1998), pages 301-314.

(1998). Logic, Logic, and Logic. Cambridge, Mass.: Harvard University Press.

Boolos, George and Richard G. Heck, Jr. (1998). 'Die Grundlagen der Arithmetik $\$ \$ 82-83$ ', in Schirn (1998), pages 407-428. Reprinted in Boolos (1998), pages 315-338.

Bostock, David (1974-79). Logic and Arithmetic. 2 vols. Oxford: Clarendon Press.

Burgess, John P. (1984). 'Review of Wright (1983)', Philosophical Review 93:638-640.

(2005). Fixing Frege. Princeton: Princeton University Press.

Clark, Peter (1993). 'Basic Law (V)-II: Sets and Indefinitely Extensible Concepts and Classes', Aristotelian Society Supplementary Volume 67:235-249.

Cook, Roy T. (2002). 'The State of the Economy: Neo-Logicism and Inflation', Philosophia Mathematica 10:43-66. Reprinted in Cook (2007), pages 197-218.

(2003a). 'Aristotelian Logic, Axioms, and Abstraction', Philosophia Mathematica 11:195-202. Reprinted in Cook (2007), page 147-153.

(2003b). 'Iteration One More Time', Notre Dame Journal of Formal Logic 44:63-92. Reprinted in Cook (2007), pages 421-454.

(2012). 'Conservativeness, Stability, and Abstraction', British Journal for the Philosophy of Science 63:673-696.

(2016). 'Frege's Cardinals and Neo-Logicism', Philosophia Mathematica. Forthcoming.

(forthcoming). 'Frege's Little Theorem and Frege's Way Out', in Ebert and Rossberg (forthcoming).

Cook, Roy T. and Philip A. Ebert (2005). 'Abstraction and Identity', Dialectica 59:121-139.

Cook, Roy T., ed. (2007). The Arché Papers on the Mathematics of Abstraction. The Western Ontario Series in Philosophy of Science. New York: Springer.

Dedekind, Richard (1872). Stetigkeit und Irrationale Zablen. Braunschweig: Friedrich Vieweg \& Sohn. English translation by Wooster W. Beman as 'Continuity and Irrational Numbers' in Dedekind (1901); reprinted, with 
“Abstractionism_OUP_for_copyediting” - 2016/4/20 - 11:40 - page 24 - \#33

corrections by William Ewald, in Ewald (1996), vol. II, pages 765-779.

Dedekind, Richard (1901). Essays on the Theory of Numbers. Translated by Wooster W. Beman. Chicago: Open Court. Reprinted by Dover, New York, 1963.

Demopoulos, William (1998). 'The Philosophical Basis of Our Knowledge of Number', Noûs 32:481-503.

- (2000). 'On The Origin And Status Of Our Conception Of Number', Notre Dame Journal of Formal Logic 41:210-226.

Demopoulos, William and Peter Clark (2005). 'The Logicism of Frege, Dedekind, and Russell', in Shapiro (2005), pages 129-165.

Demopoulos, William, ed. (1995). Frege's Philosophy of Mathematics. Cambridge, Mass.: Harvard University Press.

Dummett, Michael (1973). 'Frege's Way Out: A Footnote to a Footnote', Analysis 33:139-140.

(1981a). Frege: Philosophy of Language, second edition. Cambridge, MA: Harvard.

(1981b). The Interpretation of Frege's Philosophy. Cambridge, MA: Harvard.

- (1991). Frege: Philosophy of Mathematics. London: Duckworth.

(1994). 'Chairman's Address: Basic Law V', Proceedings of the Aristotelian Society 94:243-251.

- (1998). 'Neo-Fregeans: In Bad Company?', in Schirn (1998), pages 369-387.

Ebels-Duggan, Sean (2015). 'The Nuisance Principle in Infinite Settings', Thought 4(4):263-268.

Ebert, Philip A. (2005). 'Transmission of warrant-failure and the notion of epistemic analyticity', Australasian Journal of Philosophy 83(4):505-521.

(2008). 'A Puzzle About Ontological Commitments', Philosophia Mathematica 16:209-226.

(2015). 'Dummett's criticism of the context principle', Grazer Philosophische Studien 92.

Ebert, Philip A. and Marcus Rossberg (2006). 'What is the Purpose of NeoLogicism?', Travaux de logique 18:33-61.

(2009). 'Ed Zalta's Version of Neo-Logicism: A Friendly Letter of Complaint', in Hannes Leitgeb and Alexander Hieke (eds.), Reduction Abstraction - Analysis (Papers from the 31st International Wittgenstein Symposium). Kirchberg: Austrian Ludwig Wittgenstein Society, pages 303309.

Ebert, Philip A. and Marcus Rossberg, eds. (forthcoming). Essays on Frege's Basic Laws of Arithmetic. Oxford: Oxford University Press.

Ebert, Philip A. and Stewart Shapiro (2009). 'The Good, the Bad and the Ugly', Synthese 170:415-441.

Eklund, Matti (2006). 'Neo-Fregean Ontology', Philosophical Issues 20:95122. 
Ewald, William Bragg, ed. (1996). From Kant to Hilbert: A Source Book in the Foundations of Mathematics. 2 vols. Oxford: Oxford University Press.

Ferreira, Fernando and Kai F. Wehmeier (2002). 'On the Consistency of the $\Delta_{1}^{1}$-CA Fragment of Frege's Grundgesetze’, Journal of Philosophical Logic 31:301-311.

Field, Hartry (1984a). 'Critical Notice of Crispin Wright: Frege's Conception of Numbers as Objects', Canadian Journal of Philosophy 14:637-662. Reprinted as 'Platonism for Cheap? Crispin Wright on Frege's Context Principle' in Field (1989), pages 147-170.

- (1984b). 'Is Mathematical Knowledge Just Logical Knowledge?', Philosophical Review 93:509-552. Reprinted, with substantial revisions, in Field (1989), pages 79-118.

(1989). Realism, Mathematics, and Modalty. Oxford: Basil Blackwell.

Fine, Kit (2002). The Limits of Abstraction. Oxford: Oxford University Press.

Frege, Gottlob (1879). Begriffsschrift: Eine der arithmetischen nachgebildete Formelsprache des reinen Denkens. Halle a. d. Saale: Verlag L. Nebert. English translation by S. Bauer-Mengelberg in van Heijenoort (1967), pages 1-82; and by T. W. Bynum in Frege (1972).

(1884). Die Grundlagen der Arithmetik. Eine logisch mathematische Untersuchung über den Begriff der Zabl. Breslau: Wilhelm Koebner. English translation: Frege (1950).

- (1893). Grundgesetze der Arithmetik. Begriffsschriftlich abgeleitet. I. Band. Jena: Verlag H. Pohle. English translation: Frege (2013).

- (1902). 'Letter to Russell, July 28, 1902', in Gottfried Gabriel, H. Hermes, F. Kambartel, Christian Thiel, and A. Veraart (eds.), Gottlob Frege: Wissenschaftlicher Briefwechsel. Hamburg: Meiner, pages 222-224. English translation: Gabriel et al. (1980).

(1903). Grundgesetze der Arithmetik. Begriffsschriftlich abgeleitet.

II. Band. Jena: Verlag H. Pohle. English translation: Frege (2013). (1950). The Foundations of Arithmetic. Translated by J. L. Austin. Oxford: Blackwell.

(1972). Conceptual Notation and Related Articles. Translated and edited by T. W. Bynum. Oxford: Clarendon Press. (1976). Wissenschaftlicher Briefwechsel, ed. Gabriel, Gottfried, Hans Hermes, Friedrich Kampbartel, Christian Thiel, and Albert Veraart. Hamburg: Felix Meiner Verlag. (2013). Basic Laws of Arithmetic, ed. and trans. P. A. Ebert and M. Rossberg. Oxford: Oxford University Press.

Gabriel, Gottfried, Hans Hermes, Friedrich Kambartel, Christian Thiel, Albert Veraart, and Brian McGuinness, eds. (1980). Gottlob Frege: Philosophical and Mathematical Correspondence. Translated by H. Kaal. Chicago: University of Chicago Press.

Geach, Peter (1955). 'Class and concept', Philosophical Review 60:535-44.

— (1956). 'On Frege's Way Out', Mind 65:408-409. 
“Abstractionism_OUP_for_copyediting” - 2016/4/20 - 11:40 - page 26 - \#35

Geach, Peter (1976). 'Critical Notice of Michael Dummett, Frege: Philosophy of Language', Mind 85:436-449.

Hale, Bob (1987). Abstract Objects. Oxford: Basil Blackwell.

(1994a). 'Is Platonism Epistemologically Bankrupt?', Philosophical Review 103:299-325. Reprinted in Hale and Wright (2001b), pages 169188.

(1994b). 'Dummett's Critique of Wright's Attempt to Resuscitate Frege', Philosophia Mathematica 2:122-147. Reprinted in Hale and Wright (2001b), pages 189-213.

(2000a). 'Abstraction and Set Theory', Notre Dame Journal of Formal Logic 41:379-398. Reprinted in Cook (2007), pages 331-352.

(2000b). 'Reals by Abstraction', Philosophia Mathematica 8(2):100123. Reprinted in Cook (2007), pages 175-196.

Hale, Bob and Crispin Wright (2000). 'Implicit Definition and the A Priori', in Paul Boghossian and Christopher Peacocke (eds.), New Essays on the A Priori. Oxford: Clarendon Press, pages 286-319. Reprinted in Hale and Wright (2001b), pages 117-150.

(2001a). The Reason's Proper Study: Essays towards a Neo-Fregean Philosophy of Mathematics. Oxford: Clarendon Press.

(2001b). 'To Bury Caesar...', in Hale and Wright (2001b), pages $335-396$.

(2005). 'Logicism in the Twenty-first Century', in Shapiro (2005), pages $166-202$.

(2008). 'Abstraction and Additional Nature', Philosophia Mathematica 16:182-208.

(2009). 'The Metaontology of Abstraction', in David Chalmers, David Manley, and Ryan Wasserman (eds.), Metametaphysics: New Essays on the Foundations of Ontology. Oxford: Oxford University Press, pages 178-212.

Hallett, Michael (1984). Cantorian set theory and limitation of size. Oxford: Clarendon Press.

Hawley, Katherine (2007). 'Neo-Fregeanism and Quantifier Variance', Aristotelian Society Supplementary Volume 81:233-249.

Hazen, Allen (1985). 'Review of Wright (1983)', Australasian Journal of Philosophy 63:251-254.

Heck, Jr., Richard G. (1996). 'The Consistency of Predicative Fragments of Frege's Grundgesetze der Arithmetik', History and Philosophy of Logic 17:209-220.

(1997a). 'Finitude and Hume's Principle', Journal of Pbilosophical Logic 26:589-617. Reprinted with a postscript in Heck (2011a), pages 237-266.

(2000). 'Syntactic Reductionism', Philosophia Mathematica 8:124-149. (2011a). Frege's Theorem. Oxford: Clarendon Press.

(2011b). 'Ramified Frege Arithmetic', Journal of Philosophical Logic 
40:715-735.

(2012). Reading Frege's Grundgesetze. Oxford: Clarendon Press.

(2014). 'Predicative Frege Arithmetic and 'Everyday' Mathematics', Philosophia Mathematica 22:279-307.

Heck, Jr., Richard G., ed. (1997b). Language, Thought and Logic: Essays in Honour of Michael Dummett. Oxford: Oxford University Press.

Hodes, Harold (1984). 'Logicism and the Ontological Commitments of Arithmetic', Journal of Philosophy 81:123-149.

Hume, David (1739/1987). A Treatise of Human Nature. Ed. by L. A. SelbyBrigge. Second, revised edition by P.H. Nidditch. Oxford: Clarendon Press.

Jané, Ignacio and Gabriel Uzquiano (2004). 'Well- and Non-Well-Founded Fregean Extensions', Journal of Philosophical Logic 33:437-465. Reprinted in Cook (2007), pages 303-329.

Kim, Joongol (2011). 'A Strengthening of the Caesar Problem', Erkenntnis 75:123-136.

Klement, Kevin C. (2002). Frege and the Logic of Sense and Reference. New York \& London: Routledge.

Kripke, Saul (1975). 'Outline of a Theory of Truth', Journal of Philosophy 72:690-716.

Landini, Gregory (2006). 'The Ins and Outs of Frege's Way Out', Philosophia Mathematica 14:1-25.

(2012). Frege's Notations: What They Are and How They Mean. New York: Palgrave Macmillan.

Leach-Krouse, Graham (2015). 'Structual Abstraction Principles', Philosophia Mathematica. Forthcoming.

Linnebo, Øystein (2004). 'Predicative Fragments of Frege Arithmetic', Bulletin of Symbolic Logic 10:153-174.

- (2010). 'Some Criteria for Acceptable Abstraction Principles', Notre Dame Journal of Formal Logic 52:331-338.

(forthcoming). Thin Objects: An Abstractionist Account. Oxford: Oxford University Press.

Linnebo, Øystein and Garbiel Uzquiano (2009). 'Which Abstraction Principles are Acceptable? some Limitative Results', British Journal for the Philosophy of Science 60:239-252.

Linnebo, Øystein, ed. (2009). The Bad Comany Problem. Special issue of Synthese, vol. 170 , no. 3 .

Linsky, Bernard and Edward N. Zalta (1995). 'Naturalized Platonism Versus Platonized Naturalism', Journal of Philosophy 92:525-555.

(2006). 'What is Neologicism?', The Bulletin of Symbolic Logic 12:6099.

Linsky, Leonard and George F. Schumm (1971). 'Frege's Way Out: A Footnote', Analysis 32:5-7.

— (1973). 'Tripping over One's Own Footnote', Analysis 34:32. 
“Abstractionism_OUP_for_copyediting” - 2016/4/20 - 11:40 - page 28 - \#37

Logan, Shay Allen (2015). 'Abstractionist Categories of Categories', Review of Symbolic Logic pages 705-721.

(2016). 'Categories for the Neologicist', Philosophia Mathematica. Forthcoming.

MacBride, Fraser (2003). 'Speaking with shadows: A study of NeoFregeanism', British Journal for the Philosophy of Science 54:103-163.

MacFarlane, John (2009). 'Double Vision: Two Questions About the NeoFregean Program', Synthese 170:443-456.

Mancosu, Paolo (2015a). 'Grundlagen, Section 64: Frege's Discussion of Definitions by Abstraction in Historical Context', History and Philosophy of Logic 36:62-89.

- (2015b). 'In Good Company? On Hume's Principle and the Assignment of Numbers to Infinite Concepts', Revierw of Symbolic Logic 8:370410.

- (forthcoming). Infinity and Abstraction. Oxford: Oxford University Press.

Parsons, Charles (1965). 'Frege's theory of numbers', in Max Black (ed.), Philosophy in America. Ithaca: Cornell University Press, pages 180-203.

Parsons, Terence (1987). 'On the Consistency of the First-Order Portion of Frege's Logical System', Notre Dame Journal of Formal Logic 28:161-168. Reprinted in Demopoulos (1995), pages 422-431.

Pedersen, Nikolaj Jang (2009). 'Solving the Caesar Problem Without Categorical Sortals', Erkenntnis 71:141-155.

Potter, Michael and Timothy Smiley (2001). 'Abstraction by recarving', Proceedings of the Aristotelian Society 101:327-38.

Potter, Michael and Peter Sullivan (2005). 'What Is Wrong With Abstraction?', Philosophia Mathematica 13:187-193.

Quine, W. V. (1955). 'On Frege's Way Out', Mind 64(254):145-159.

Rayo, Agustín (2002). 'Frege's Unofficial Arithmetic', Journal of Symbolic Logic 67(4):1623-1638. Reprinted in Cook (2007), pages 155-172.

(2003). 'Success by Default?', Philosophia Mathematica 11(3):305-322.

(2005). 'Logicism Reconsidered', in Shapiro (2005), pages 203-235.

Press.

Reck, Erich (2013). 'Frege or Dedekind? Towards a Reevaluation of their Legacies', in Erick Reck (ed.), The Historical Turn in Analytic Philosophy. London: Palgrave, pages 139-170.

- (forthcoming). 'Frege's Relation to Dedekind: Basic Lawes and Beyond', in Ebert and Rossberg (forthcoming).

Schirn, Matthias, ed. (1996). Frege: Importance and Influence. Berlin and New York: de Gruyter. Press.

(1998). The Philosophy of Mathematics Today. Oxford: Clarendon

Shapiro, Stewart (1991). Foundations without foundationalism: a case for 
second-order logic. Oxford: Clarendon Press.

(2000). 'Frege Meets Dedekind: A Neologicist Treatment of Real Analysis', Notre Dame Journal of Formal Logic 41:335-364. Reprinted in Cook (2007), pages 219-252.

(2003). 'Prolegomenon To Any Future Neo-Logicist Set Theory: Abstraction And Indefinite Extensibility', British Journal for the Philosophy of Science 54:59-91. Reprinted in Cook (2007), pages 353-382.

Shapiro, Stewart and Geoffrey Hellman (2016). 'Frege Meets Aristotle: Points as Abstracts', Philosophia Mathematica. Forthcoming.

Shapiro, Stewart and Øystein Linnebo (2015). 'Frege Meets Brouwer (or Heyting or Dummett)', Review of Symbolic Logic 8:540-552.

Shapiro, Stewart and Alan Weir (1999). 'New V, ZF and Abstraction', Philosophia Mathematica 7:293-321. Reprinted in Cook (2007), pages 275302.

(2000). 'Neo-Logicist' Logic is Not Epistemically Innocent', Philosophia Mathematica 8:160-189. Reprinted in Cook (2007), pages 119146.

Shapiro, Stewart, ed. (2005). The Oxford Handbook of Philosophy of Mathematics and Logic. Oxford: Oxford University Press.

Sider, Theodore (2007). 'Neo-Fregeanism and Quantifier Variance', Aristotelian Society Supplementary Volume 81:201-232.

Sobociński, Boleław (1949-1950). 'L'analyse de l'antinomie russellienne par Leśniewski', Methodos 1-2:94-107, 220-228, 308-316; 6-7, 237-257. English translation by E. Clay: Sobociński (1984).

(1984). 'Leśniewski's Analysis of Russell's Paradox', in J. T. J. Srzednicki, V. F. Rickey, and J. Czelakowski (eds.), Leśniewski’s Systems: Ontology and Mereology. Boston: Martinus Nijhoff, pages 11-44.

Stein, Howard (1990). 'Exodus and Dedekind: On the Ancient Greek Theory of Ratios and its Relation to Modern Mathematics', Synthese 84:153182. Partially reprinted in Demopoulos (1995), pages 334-357.

Stirton, William (2003). 'Caesar Invictus', Philosophia Mathematica 11:285304.

Studd, James (forthcoming). 'Abstraction Reconceived', British Journal for the Philosophy of Science.

Sullivan, Peter and Michael Potter (1997). 'Hale on Caesar', Philosophia Mathematica 5:135-152.

Tait, William W. (1996). 'Frege versus Cantor and Dedekind: On the Concept of Number', in Schirn (1996), pages 70-113. Reprinted in Tait (1997), pages 213-248.

Tait, William W., ed. (1997). Early Analytic Philosophy: Frege, Russell, Wittgenstein. Essays in Honor of Leonard Linsky. La Salle, Ill.: Open Court Press.

Tennant, Neil (1987). Anti-Realism and Logic: Truth as Eternal. Clarendon Library of Logic and Philosophy. Oxford: Oxford University Press.

(2009). 'Natural Logicism via the Logic of Orderly Pairing', in Sten 
“Abstractionism_OUP_for_copyediting” - 2016/4/20 - 11:40 - page 30 - \#39

Lindström, Erik Palmgren, Krister Segerberg, and Viggo StoltenbergHansen (eds.), Logicism, Intuitionism, Formalism: What has become of them? Dordrecht \& London: Springer, pages 91-125.

Tennant, Neil (2014). 'Logicism and Neologicism', in Edward N. Zalta (ed.), The Stanford Encyclopedia of Philosophy, Fall 2014 edition. http://plato.stanford.edu/archives/fall2014/entries/logicism/.

Thomas, Morgan (ms). 'Set theory via abstraction', manuscript, 2015.

Urbaniak, Rafał (2010). 'Neologicist Nominalism', Studia Logica 96:149-173. van Heijenoort, Jean, ed. (1967). From Frege to Gödel: A Source Book in Mathematical Logic, 1879-1931. Cambridge, Mass.: Harvard University Press.

Visser, Albert (2009). 'The predicative Frege hierarchy', Annals of Pure and Applied Logic 160:129-153.

Walsh, Sean (2012). 'Comparing Peano Arithmetic, Basic Law V and Hume's Principle', Annals of Pure and Applied Logic 163:1679-1709.

- (2014). 'Logicism, Interpretability, and Knowledge of Arithmetic', Review of Symbolic Logic 7:84-119.

(2015). 'Fragments of Frege's Grundgesetze and Gödel's Constructible Universe', Journal of Symbolic Logic. Forthcoming.

(2016). 'The strength of abstraction with predicative comprehension', Bulletin of Symbolic Logic 22:105-120.

Walsh, Sean and Sean Ebels-Duggan (2015). 'Relative Categoricity and Abstraction Principles', Review of Symbolic Logic 8:572-606.

Wehmeier, Kai F. (1999). 'Consistent Fragments of Grundgesetze and the Existence of Non-Logical Objects', Synthese 121:309-328.

Weir, Alan (2003). 'Neo-Fregeanism: An Embarrassment of Riches', Notre Dame Journal of Formal Logic 44:13-48. Reprinted in Cook (2007), pages 383-420.

Wilson, Mark (1992). 'Frege: The Royal Road from Geometry', Nô̂s 26:149180. Reprinted in Demopoulos (1995).

(2010). 'Frege's mathematical setting', in Michael Potter and Tom Ricketts (eds.), The Cambridge Companion to Frege. Cambridge: Cambridge University Press, pages 379-413.

Wright, Crispin (1983). Frege's Conception of Numbers as Objects. Aberdeen: Aberdeen University Press.

(1997). 'On the Philosophical Significance of Frege's Theorem', in Heck (1997b), pages 201-244. Reprinted in Hale and Wright (2001b), pages $272-306$.

(1998a). 'On the Harmless Impredicativity of $\mathrm{N}^{=}$('Hume's Principle')', in Schirn (1998), pages 339-368. Reprinted in Hale and Wright (2001b), pages 339-368.

(1998b). 'Response to Dummett', in Schirn (1998), pages 389-405. Reprinted in Hale and Wright (2001b), pages 256-271.

(1999). 'Is Hume's Principle Analytic?', Notre Dame Journal of Formal Logic 40:6-30. Reprinted in Hale and Wright (2001b), pages 307-332. 
(2000). 'Neo-Fregean Foundations for Real Analysis: Some Reflections on Frege's Constraint', Notre Dame Journal of Formal Logic 41:317334. Reprinted in Cook (2007), pages 253-272.

Yap, Audrey (forthcoming). 'Dedekind and Cassirer on Mathematical Concept Formation', Philosophia Mathematica.

Zalta, Edward N. (1999). 'Natural Numbers and Natural Cardinals as Abstract Objects: A Partial Reconstruction of Frege's Grundgesetze in Object Theory', Journal of Philosophical Logic 28:610-660.

(2000). 'Neo-Logicism? An Ontological Reduction of Mathematics to Metaphysics', Erkenntnis 53:219-265.

(2009). 'Reply to P. Ebert and M. Rossberg's Friendly Letter of Complaint', in Hannes Leitgeb and Alexander Hieke (eds.), Reduction - Abstraction - Analysis (Papers from the 31st International Wittgenstein Symposium). Kirchberg: Austrian Ludwig Wittgenstein Society, pages 311-318. 